\title{
Biodiesel production from microalgae
}

\author{
M. Veillette ${ }^{1}$, A. Giroir-Fendler ${ }^{2}$, N. Faucheux ${ }^{1} \&$ M. Heitz ${ }^{1}$ \\ ${ }^{I}$ Department of Chemical Engineering and Biotechnological \\ Engineering, Engineering Faculty, Université de Sherbrooke, Canada \\ ${ }^{2}$ Université de Lyon, France
}

\begin{abstract}
By 2020, according to several government policies like the European Union countries, road transportation fuels must contain at least $10 \%(\mathrm{v} / \mathrm{v})$ biofuel like biodiesel. Consequently, the world biodiesel production is expected to rise in the next years. However, most biodiesel is produced from vegetable oils, which compete with human food production. Biodiesel from microalgae could help to reach the requested level of biofuel (biodiesel) without endangering the world food supply because microalgae cultivation does not compete with arable land. Nevertheless, the cost of biodiesel production from microalgae must be lowered. One of the main challenges is to extract the lipids from the microalgae and to transform them into biodiesel.

The $1^{\text {st }}$ objective of this study was therefore to compare chloroformmethanol-water and hexane as solvents for Nannochloropsis Oculata, Isochrysis Galbana and Pavlova Lutheri microalgae lipid extraction. The $2^{\text {nd }}$ objective was to transform the lipids into biodiesel by an acid catalysed (acetyl chloride) transesterification. The results obtained demonstrated that a lipid yield of $32 \%$ $(\mathrm{w} / \mathrm{w})$ could be obtained by an extraction with chloroform-methanol-water without reflux. With hexane reflux, the lipids extracted from the microalgae reached $22 \%(\mathrm{w} / \mathrm{w})$. The fatty acid methyl ester (FAME) composition was not influenced by the reflux (chloroform-methanol-water) during the solvent extraction. The main FAME weight composition (\% wt.) obtained from an acid catalyzed transesterification $\left(100^{\circ} \mathrm{C}, 1 \mathrm{~h}\right)$ were methyl palmitoleate $(56-58 \%)$, methyl palmitate (12-14\%) and methyl eicosapentaenoate (9.6-10.1\%).
\end{abstract}

Keywords: biodiesel, microalgae, extraction, lipids, transesterification, FAME. 


\section{Introduction}

Oil is a major source of energy. From 1999 to 2009, the world crude oil consumption increased from 75.6 to 84.1 million barrels per day [1]. Consequently, the quest for new petroleum deposits harder to extract increases the risk of environmental disasters like the 2010 oil spill in the United States of America [2]. Moreover, the use of fossil-fuels has a negative impact on the global carbon mass balance.

In order to reduce their fossil-fuel consumption, several governments like European Union countries have formulated policies, which state that petroleumbased fuels must contain at least $10 \%(\mathrm{v} / \mathrm{v})$ biofuel (bioethanol and biodiesel) by 2020 [3]. Other countries like the United States of America intend to increase the annual biofuel production from 9 to 36 billion gallons between 2008 and 2022 [4]. It is to be noted that the world annual biodiesel production has increased from 1.2 to 4.7 billion gallons between 2005 and 2009 [5]. However, the fact that most biodiesel is produced from oleaginous materials such as soybean cultivated on arable land could lead to land pollution, world hunger and deforestation [6]. Biodiesel from microalgae seems an interesting avenue to replace vegetablebased biodiesel because microalgae culture does not compete with food crops. However, the production costs of microalgae biodiesel are still high, between 2.4 to $6.6 \$ \mathrm{US} / \mathrm{L}[7]$.

Some studies have used direct transesterification (without prior lipid extraction) to produce biodiesel from microalgae $[8,9]$, but this process requires more energy (up to 2.5 times) for microalgae drying than a process with prior extraction [10].

Intending to replace lipid chloroform-methanol-water extraction, some studies used Soxhlet hexane extraction to extract lipids from Neochloris oleabundans microalgae and obtained a high lipid yield of $56 \%(\mathrm{w} / \mathrm{w})$, compared to the values generally found in the literature $(35-65 \% \mathrm{w} / \mathrm{w})$ [11]. However, Soxhlet extraction requires an important amount of energy [12].

The main goal of this study is to compare the existing extraction methods to determine which is the most suitable to extract lipids from a blend of microalgae (Nannochloropsis Oculata, Isochrysis Galbana and Pavlova Lutheri). The $2^{\text {nd }}$ purpose of this study is to determine if the fatty acid methyl ester (FAME) content obtained from an acid transesterification is suitable for biodiesel production.

\section{Materials and methods}

\subsection{Feedstock and solvent}

A frozen microalgae blend (Nannochloropsis Oculata, Isochrysis Galbana and Pavlova Lutheri) was supplied by Nutrocéan Canada (Rimouski, Canada). Table 1 presents the elemental composition of the microalgae. Frozen microalgae were lyophilized at $-50^{\circ} \mathrm{C}$ using a Virtis specimen freeze drier (model 24DX24, Gardiner, New York, USA) for 5 days and lyophilized microalgae were stored at $-20^{\circ} \mathrm{C}$. 
Table 1: Elemental composition of frozen microalgae.

\begin{tabular}{|c|c|}
\hline & $\%(\mathrm{w} / \mathrm{w})$ \\
\hline Moisture & $83.9 \pm 0.05$ \\
\hline Solids & $16.1 \pm 0.05$ \\
\hline Volatile matter & $12.8 \pm 0.30$ \\
\hline Ash & $3.3 \pm 0.25$ \\
\hline
\end{tabular}

Chloroform $\left(\mathrm{CHCl}_{3}\right)$, methanol $(\mathrm{MeOH})$ and hexane $\left(\mathrm{C}_{6} \mathrm{H}_{14}\right)$ certified ASC solvents were supplied by Fischer Scientific inc. (Canada) while acetyl chloride $\left(\mathrm{CH}_{3} \mathrm{COCl}\right)(99 \%$ pure) was supplied by Fluka (Oakville, USA).

\subsection{Lipid extraction}

Table 2 summarizes the methodology of all the lipid extraction experiments. Chloroform-methanol-water extraction was performed in experiments 1 and 2 using a modified procedure of Lee et al. [13]. Hexane extraction was used in a $3^{\text {rd }}$ experiment. Briefly, in the $1^{\text {st }}$ and $2^{\text {nd }}$ experiments, lyophilized microalgae were dissolved in $100 \mathrm{~mL}$ of chloroform-methanol $(1: 1, \mathrm{v} / \mathrm{v})$. In the $2^{\text {nd }}$ experiment, the blend (solvents-microalgae) was heated under reflux for $5 \mathrm{~min}$ and then cooled off, while in the $1^{\text {st }}$ experiment no heating of the blend was applied. For both experiments, the blend was then transferred into a separation funnel and $100 \mathrm{~mL}$ of water was added. The separation funnel was shaken for 1 min and the bottom phase (chloroform-lipids) was recovered after settling (1h).

Table 2: $\quad$ Lipids extraction experiments.

\begin{tabular}{|c|c|c|c|c|}
\hline Exp. & Solvent treatment & Reflux & Solvent addition & Separation \\
\hline 1 & Chloroform-methanol & No & Water & Settling \\
\hline 2 & Chloroform-methanol & Yes & Water & Settling \\
\hline 3 & Hexane & Yes & & Filtration \\
\hline
\end{tabular}

In the $3^{\text {rd }}$ experiment, the lyophilized biomass was dissolved in $100 \mathrm{~mL}$ of hexane and heated under reflux. The blend was cooled off and filtered with a filter paper (Whatman \#1).

For all the experiments, the solvent was evaporated under vacuum at $60^{\circ} \mathrm{C}$ and the lipids were quantified using an electronic scale (Mettler Toledo AT200). All the lipid extraction results were a mean of 3 replicates and expressed as a function of the dry weight. One-way ANOVA and Turkey tests $(\mathrm{P}<0.05)$ were used to compare the different treatments.

\subsection{Transesterification of lipids and biodiesel recovery}

Crude lipids obtained were transesterified using a modified procedure of Lepage and Roy [14]. Four $\mathrm{mL}$ of a freshly made methanol-acetyl chloride $(100: 5, \mathrm{v} / \mathrm{v})$ solution was added to the extracted lipids. The blend was heated at $100^{\circ} \mathrm{C}$ (water bath) for $1 \mathrm{~h}$ (with agitation at $1200 \mathrm{rpm}$ ) under a reflux. The excess of methanol was evaporated at $60^{\circ} \mathrm{C}$ under a vacuum. Then, $20 \mathrm{~mL}$ of hexane was used to 
separate biodiesel from other components (mainly glycerol and chlorophyll insoluble in hexane) [12]. Hexane was evaporated at $60^{\circ} \mathrm{C}$ under vacuum.

\subsection{Analytical methods}

The FAME qualitative composition of biodiesel was determined using a Varian3800 gas chromatograph equipped with a mass spectrometer (Varian Inc, Canada). An external standard of 37 FAMEs (Supelco, 18919-1AMP) was used for FAME identification. One $\mu \mathrm{L}$ of hexane-biodiesel was injected in a DB-225 cyanopropylphenyl-dimethylpolysiloxane capillary column $(30 \mathrm{~m}$ x $0.25 \mathrm{~mm}$ I.D., $0.25 \mu \mathrm{m}$ film thickness). Helium, used as carrier gas, was set to a flow rate of $2.2 \mathrm{~mL} / \mathrm{min}$ with a split ratio of $100: 1$. The oven was heated at $70^{\circ} \mathrm{C}$ for $1 \mathrm{~min}$, from 70 to $180^{\circ} \mathrm{C}$ at $20^{\circ} \mathrm{C} / \mathrm{min}$, from 180 to $220^{\circ} \mathrm{C}$ at $3{ }^{\circ} \mathrm{C} / \mathrm{min}$ and maintained at $220^{\circ} \mathrm{C}$ for $1 \mathrm{~min}$. The FAME quantitative composition was determined using a flame ionisation detector (FID), and external standards (Supelco, GLC-10, GLC50, GLC-80, 18913-1AMP). Pure hydrogen gas $\left(\mathrm{H}_{2}\right)$ was used to feed the FID at a temperature of $240^{\circ} \mathrm{C}$ and nitrogen was used as a make-up gas at a flow rate of $30 \mathrm{~mL} / \mathrm{min}$. The FAME composition was an average of 3 replicates. The lipid yields of different treatments were compared using one-way ANOVA and Tukey tests with $\mathrm{P}<0.05$.

\subsection{Cetane number}

The cetane number is an indicator of the quality of a fuel ignition [15]. The cetane number of the biodiesel was estimated from correlations with the FAME weight percentage as follows [16]:

$$
C N=1.068 \cdot \sum\left(C N_{i} m_{i}\right)-6.747
$$

where $\mathrm{CN}$ is the cetane number, $\mathrm{CN}_{\mathrm{i}}$ is the cetane number of $\mathrm{FAME}_{\mathrm{i}}$ and $\mathrm{m}_{\mathrm{i}}$ is the mass percentage of FAME $E_{i}$. The cetane number of individual FAME $\left(\mathrm{CN}_{\mathrm{i}}\right)$ was estimated as follows [17]:

$$
C N_{i}=-23.523+n \cdot\left(2.366+6.299 \cdot e^{-0.411 \cdot d b}\right) \cdot e^{-0.018 \cdot n}
$$

where $\mathrm{db}$ is the number of double bounds on the acid chain and $\mathrm{n}$ is the acid chain length. Table 3 presents the cetane number of individual FAME.

Table 3: $\quad$ Cetane number of different individual FAMEs.

\begin{tabular}{|c|c|}
\hline FAME & Cetane number \\
\hline C14:0 & 70.8 \\
\hline C16:0 & 80.4 \\
\hline C16:1 $18: 1$ & 55.0 \\
\hline C18:2 & 61.6 \\
\hline C18:3 & 43.3 \\
\hline C20:4 & 31.2 \\
\hline C20:5 & 26.5 \\
\hline C22:6 & 20.7 \\
\hline
\end{tabular}




\section{Results and discussion}

\subsection{Extraction of lipids}

Table 4 presents the results for both chloroform-methanol-water and hexane extractions. The lipid content obtained from the microalgae blend varied from 22 to $33 \%(\mathrm{w} / \mathrm{w})$.

Table 4: $\quad$ Results of chloroform-methanol-water and hexane extraction.

\begin{tabular}{|c|c|}
\hline & $\begin{array}{c}\text { Lipid content } \\
(\% \mathrm{w} / \mathrm{w})\end{array}$ \\
\hline Chloroform-methanol-water & $32.0 \pm 1.2$ \\
\hline Reflux chloroform-methanol-water & $33.0 \pm 0.1$ \\
\hline Reflux hexane-filtration & $22.4 \pm 0.6$ \\
\hline
\end{tabular}

In a study using water-chloroform-methanol $(2: 1: 1, \mathrm{v} / \mathrm{v})$ to extract lipids from different lyophilized microalgae (Botryococcus sp., Chlorella vulgaris, Scenedesmus sp.), Lee et al. [13] used several pre-treatments in water phase (autoclave, microwave, sonication, osmotic shock) and obtained a lipid content from 1.8 to $28.6 \%(\mathrm{w} / \mathrm{w})$. Consequently, the lipid content $(32-33 \% \mathrm{w} / \mathrm{w})$ obtained by chloroform-methanol-water extraction from the blend of microalgae (Nannochloropsis Oculata, Isochrysis Galbana and Pavlova Lutheri) in the present study seems to be promising for biodiesel production as some Botryococcus species like Botryococcus braunii used in Lee et al. [13] study can contain up to $75 \%(\mathrm{w} / \mathrm{w})$ lipids.

No significant difference was observed between both chloroform-methanolwater lipid extractions ( $1^{\text {st }}$ and $2^{\text {nd }}$ experiments). Consequently, chloroformmethanol-water extraction could be used to obtain lipids without reflux.

Both chloroform-methanol-water extractions gave a significant higher lipid yield $(32.5 \pm 0.5 \% \mathrm{w} / \mathrm{w})$ than hexane extraction under reflux $(22 \% \mathrm{w} / \mathrm{w})$. The fact that a lower lipid content was obtained with hexane extraction compared to chloroform-methanol-water could be the consequence of the non-polar nature of hexane. In fact, some polar lipids like glycolipids and phospholipids could not be extracted with hexane. It is known that some microalgae like Nannochloropsis oculata and Isochrysis species can contain up to 77 and $62 \%(\mathrm{w} / \mathrm{w})$ of glycolipids and phospholipids (combined), respectively [18]. Some studies used hexane-isopropanol instead of chloroform-methanol-water to extract Botryococcus braunii (UTEX 572) lipids and obtained a 1.4 times lower lipid content [19].

\subsection{FAME composition}

Figure 1 presents the FAME composition of the biodiesel produced for both chloroform-methanol-water. The weight composition remains relatively constant no matter if a reflux was used or not to recover the lipids in microalgae. The 


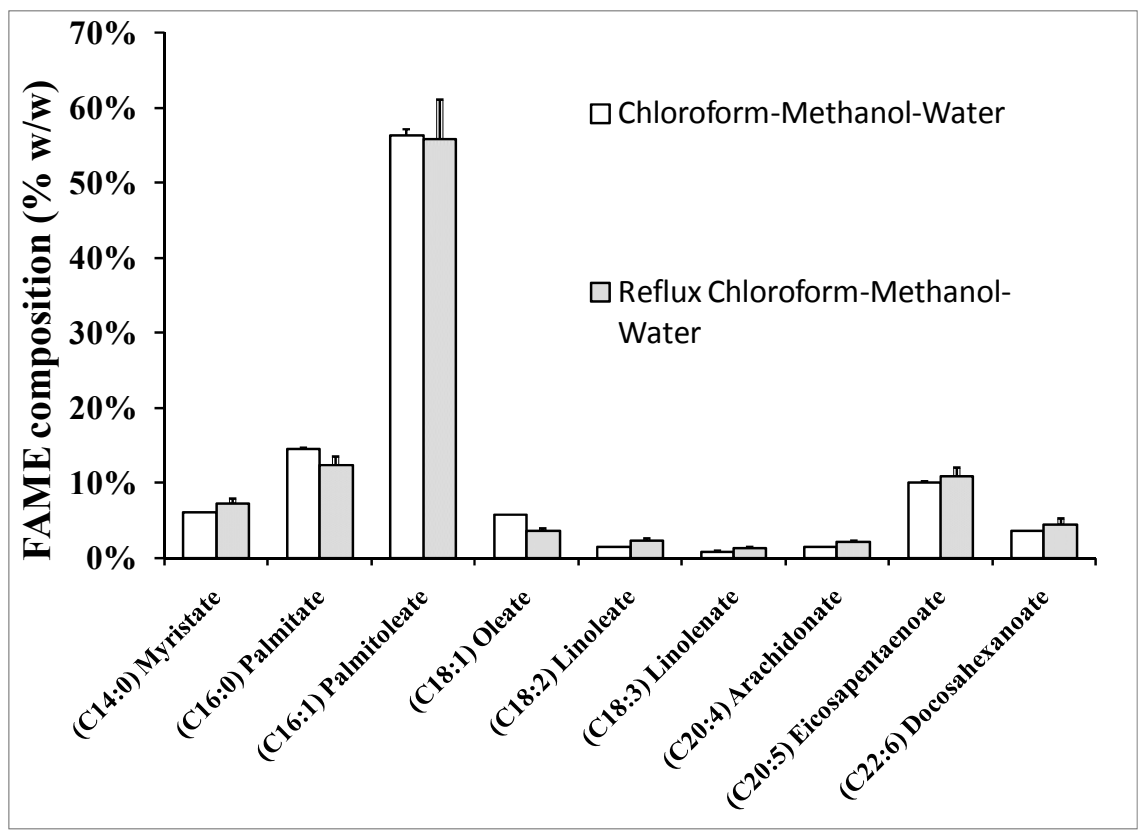

Figure 1: $\quad$ FAME weight composition as a function of the extraction method.

main FAME components were (\% wt.): methyl palmitoleate (55.7-58\%), methyl palmitate (12.3-14.5\%), methyl eicosapentaenoate (9.6-10.9\%) and methyl docosahexanoate $(6.1-7.3 \%)$.

As seen in Figure 1, using a reflux chloroform-methanol-water for microalgae lipid extraction did not influence the FAME composition of the biodiesel. Based on our present knowledge, no study has compared the difference between using a reflux or not in chloroform-methanol-water extraction in terms of FAME composition. However, other studies have found that the nature of the extraction solvent (hexane, alcohol, etc.) does not influence the FAME composition [20].

The fact that around $80 \%(\mathrm{w} / \mathrm{w})$ of the FAME was composed of monounsaturated (MFA) and saturated (SFA) FAME is interesting for biodiesel production. In fact, the main problem with biodiesel produced from microalgae is polyunsaturated FAME (PFA) ( $>2$ double bounds) content up to $59 \%(\mathrm{w} / \mathrm{w})$ $[9,16,21]$ that causes a low cetane number and poor oxidation stability [16].

The cetane number approximated by calculation was $50.8 \pm 0.8$, which is over the ASTM standard of 47 [22]. Other studies estimated the cetane number of several microalgae such as Isochrysis galbana, Odontella weissflogi and Chaetoceros sp. with a similar method and found cetane numbers ranging from 39 to 54 [16].

Based on our present knowledge, there is no model to estimate the oxidation stability, but antioxidants can be added to biodiesel from microalgae to increase the oxidation stability [22]. 


\section{Conclusion}

In order to replace conventional oleaginous vegetable-based biodiesel, which is among others a risk for food security, the lipid extraction from a blend of microalgae (Nannochloropsis Oculata, Isochrysis Galbana and Pavlova Lutheri) was studied. The lipid content obtained was $32 \%(\mathrm{w} / \mathrm{w})$ for chloroformmethanol-water extraction while hexane reflux extraction conducted to $22 \%$ (w/w).

The FAME content of the biodiesel produced after chloroform-methanolwater lipid extractions with and without reflux showed good properties in terms of cetane number (50.8) and oxidation stability as the PFA content was low at around $20 \%(\mathrm{w} / \mathrm{w})$.

\section{Acknowledgements}

The authors are grateful to le Fond Québécois de la Recherche sur la Nature et les Technologies (FQRNT) for the grant to Michèle Heitz and Nathalie Faucheux for the research program in partnership contributing to the reduction of greenhouse gases. The authors would like to thank Professors Jean-Sébastien Deschênes (Department of Mathematics, Computer Science and Engineering) and Réjean Tremblay (Institute of Ocean Sciences) at the University of Rimouski for their contribution to the research project by providing the microalgae. Thanks also have to be expressed to the Biology Department of Université de Sherbrooke for the use of the lyophilisation apparatus.

\section{References}

[1] BP, BP Statistical Review of World Energy, 2011, http://www.bp.com /liveassets/bp internet/globalbp/globalbp uk english/reports and publicati ons/statistical_energy_review_2011/STAGING/local_assets/pdf/statistical_ review_of_world_energy_full_report_2011.pdf

[2] Gillis, J. \& Fountain, H., New estimates double rate of oil flowing into gulf. The New York Times, pp. A1, 2010, http://www.nytimes.com/2010/06/11/us $/ 11$ spill.html

[3] Bindraban, P.S., Bulte, E.H. \& Conijn, S.G., Can large-scale biofuels production be sustainable by 2020? Agricultural Systems, 101, pp. 197-199, 2009.

[4] FAO, Biofuels: prospects, risks and opportunities. The state of food and agriculture, 2008, ftp://ftp.fao.org/docrep/fao/011/i0100e/i0100e.pdf

[5] U.S. Energy Information Administration, International energy statistics: Biodiesel production, 2010, http://www.eia.gov/cfapps/ipdbproject/docs /schedule_updates.cfm

[6] Goldemberg, J. \& Guardabassi, P., Are biofuels a feasible option? Energy Policy, 37(1), pp. 10-14, 2009. 
[7] Singh, J. \& Gu, S., Commercialization potential of microalgae for biofuels production. Renewable and Sustainable Energy Reviews, 14(9), pp. 25962610, 2010.

[8] Koberg, M., Cohen, M., Ben-Amotz, A. \& Gedanken, A., Bio-diesel production directly from the microalgae biomass of Nannochloropsis by microwave and ultrasound radiation. Bioresource Technology, 102, pp. 4265-4269, 2011.

[9] Johnson, M.B. \& Wen, Z., Production of biodiesel fuel from the microalga Schizochytrium limacinum by direct transesterification of algal biomass. Energy Fuels, 23, pp. 5179-5183, 2009.

[10] Lardon, L., Hélias, A., Sialve, B., Steyer, J. \& Bernard, O., Life-cycle assessment of biodiesel production from microalgae. Environmental Science and Technology, 43(17), pp. 6475-6481, 2009.

[11] Gouveia, L. \& Oliveira, A.C., Microalgae as a raw material for biofuels production. Journal of Industrial Microbiology and Biotechnology, 36(2), pp. 269-274, 2009.

[12] Halim, R., Gladman, B., Danquah, M.K. \& Webley, P.A., Oil extraction from microalgae for biodiesel production. Bioresource Technology, 102(1), pp. 178-185, 2010.

[13] Lee, J., Yoo, C., Jun, S., Ahn, C. \& Oh, H., Comparison of several methods for effective lipid extraction from microalgae. Bioresource Technology, 101, pp. 575-577, 2010.

[14] Lepage, G. \& Roy, C.C., Improved recovery of fatty acid through direct transesterification without prior extraction or purification. Journal of Lipid Research, 25(12), pp. 1391-1396, 1984.

[15] Knothe, G., Cetane numbers-heat of combustion-why vegetable oils and their derivatives are suitable as a diesel fuel (Chapter 6.1). The biodiesel handbook, ed. G. Knothe, J. Krahl \& J. V. Gerpen, AOCS Press: Campaign, Illinois, USA, pp. 72-80, 2005.

[16] Stansell, G.R., Gray, V.M. \& Sym, S.D., Microalgal fatty acid composition: implications for biodiesel quality. Journal of Applied Phycology, Published online: June 302011.

[17] Lapuerta, M., Rodríguez-Fernández, J. \& Armas, O., Correlation for the estimation of the density of fatty acid esters fuels and its implications. A proposed biodiesel cetane index. Chemistry and Physics of Lipids, 163, pp. 720-727, 2010.

[18] Williams, P.J. \& Laurens, L.M., Microalgae as biodiesel and biomass feedstocks: Review and analysis of the biochemistry, energetics and economics. Energy \& Environmental Science, 3, pp. 554-590, 2010.

[19] Lee, S., Yoon, B. \& Oh, H., Rapid method for the determination of lipid from the green alga Botryococcus braunii. Biotechnology Techniques, 12(7), pp. 553-556, 1998.

[20] Samorì, C., Torri, C., Samorì, G., Fabbri, D., Galletti, P., Guerrini, F., Pistocchi, R. \& Tagliavini, E., Extraction of hydrocarbons from microalga Botryococcus braunii with switchable solvents. Bioresource technology, 101(9), pp. 3274-3279, 2010. 
[21] Lewis, T., Nichols, P.D. \& McMeekina, T.A., Evaluation of extraction methods for recovery of fatty acids from lipid-producing microheterotrophs. Journal of Microbiological Methods, 42, pp. 107-116, 2000.

[22] ASTM Standard D6751-10, 2010, "Standard specification for biodiesel fuel blend stock (B100) for middle distillate fuels," ASTM International, 2010, DOI: 10.1520/D6751-10, West Conshohocken, PA, www.astm.org. 